\title{
AS REGRAS DA ARTE E A QUEDA DA AURÉOLA: REFLEXOOES SOBRE O VALOR DA ARTE E LITERATURA HOJE
}

THE RULES OF ART AND THE FALL OF THE AUREOLA: ISSUES ABOUT THE VALUE OF ART AND LITERATURE NOWADAYS

Eloisa da Rosa Oliveira ${ }^{1}$ 


\section{Resumo}

Este artigo aborda o tema da distinção existente entre a arte ordinária e extraordinária e os caminhos que a avaliação da arte tem tomado em nossa sociedade pós-moderna. Como escopo do estudo, o foco foi dado ao campo da arte literária em diálogo com o campo das artes visuais. A problematização está no julgamento do gosto e sacralização de obras artísticas. Para isso, o ponto chave do debate se apoia em Pierre Bourdieu - mais especificamente em suas obras Distinção (2013) e As Regras da Arte (2015) - para pensar no valor da obra de arte hoje, na "autonomia" do artista e, por último, na perspectiva do leitor de obras literárias e sua relação com essas classificações. O objetivo central do estudo foi, portanto, desdobrar os temas aqui expostos a fim de compreender melhor o lugar da arte e seus critérios de avaliação dentro de alguns dispositivos de poder, que, por vezes, exercem uma "violência simbólica" (BOURDIEU, 1989).

Palavras-chave: Distinção cultural. Literatura. Valor Simbólico. Arte.

\section{Abstract}

This article is about the distinction between extraordinary and ordinary art and the directions that the art evaluation has taken in our post-modernity society. The scope here is the literary art campus, including some relevant questions regarding to visual arts. The principal issue is the judgment of taste and the process that intends to turn the art in something sacred. Pierre Bourdieu is the central author in this study - especially in his books Distinction and The rules of the art - where he approaches questions about the value of art and the artist's autonomy. Another important point is to wonder about the position of the readers and students nowadays in relation to these rules. Finally, it is concerned in discussing how art and these rules are connected with any kind of symbolic violence.

Keywords: Cultural distinction. Literature. Symbolic Value. Art.

ISSN: 2175-2346 


\section{Proposições iniciais}

\section{A PERDA DA AURÉOLA}

-O quê? Você por aqui, meu caro? Num lugar suspeito? Você, o bebedor de quintessências? O comedor de ambrosia? Na verdade, tenho de surpreender-me!-Você conhece, caro amigo, meu pavor pelos cavalos e pelos carros.

Ainda há pouco, quando atravessava a avenida, apressadíssimo, e saltitava na lama em meio a esse caos movediço em que a morte chega a galope por todos os lados ao mesmo tempo, minha auréola, num movimento brusco, escorregou da minha cabeça para a lama da calçada. Não tive coragem de juntá-la. Julguei menos desagradável perder minhas insígnias do que deixar que me rompessem os ossos. E depois, pensei, há males que vêm para bem. Posso agora passear incógnito, praticar ações vis e me entregar à devassidão, como os simples mortais. E aqui estou, igualzinho a você, como vê!

-Você deveria ao menos mandar pôr um anúncio pela auréola, ou mandar reavê-la pelo delegado.

-Não, ora essa! Sinto-me bem aqui. Só você me reconheceu. A dignidade, aliás, me entedia. E também, me alegra pensar que algum poeta ruim há de juntá-la e vesti-la impudentemente. Fazer alguém feliz, que prazer! Principalmente um feliz que ainda vai me fazer rir! Pense em $X$ ou em $Z$, puxa! Que engraçado vai ser!

Charles Baudelaire, em Pequenos poemas em prosa (1995, p.73).

Charles Baudelaire representa um marco entre poetas do século XIX, conhecido por interpretar os movimentos da modernidade, sobretudo no campo da arte. Assim, ele metamorfoseou os elementos sociais observados em poesia. Como no caso de "A perda da Auréola", o poeta da modernidade cria uma alegoria sobre a posição social do poeta em decadência. Visto como sujeito de prestígio, a figura do poeta no século XIX carrega uma auréola sobre si que reserva a ele um lugar sagrado e intocável. Nessa alegoria apresentada no poema de epígrafe, Baudelaire (1995) retrata o poeta que perde essa auréola na lama e, ao contrário do que se espera, não se importa com isso. A partir daí, o tom de sarcasmo questiona essa posição sagrada e o poeta comemora a liberdade de seu novo lugar, agora em meio aos "mortais", aonde nem sequer será reconhecido. A cena poética, trazida aqui como motivação para este texto, ainda hoje pode ser observada no campo da arte, uma vez que essa distinção entre "artista-com-auréola" e "artista-sem-auréola" ainda permeia os debates em voga na atualidade.

Para relacionar esse contexto apresentado por Baudelaire (1995) com a pós-modernidade e século XXI no campo das artes, trago o problema chave deste artigo: o modo como a avaliação e valorização de obras artísticas ${ }^{1}$ interfere no julgamento do gosto cultural e reforça a sacralização da arte. Desse modo, os capítulos seguintes irão desenvolver debate sobre os temas subsequentes: em primeiro momento, problematizo a diferença entre o valor e valorização da obra de arte hoje no intuito de entender quais são os critérios que permitem que uma obra seja classificada como

\footnotetext{
1 Ao longo deste artigo, quando me refiro a "obras de arte" ou "obras artísticas", estou fazendo menção a trabalhos de cunho artístico que circulam em nossa sociedade tanto no campo da escrita (literário), auditivo (musical) ou visual (telas, esculturas, performances, entre outras possibilidades inerentes ao campo). Em alguns momentos do texto, quando menciono obra de arte de modo mais generalizado posso estar me referindo tanto à obra literária quanto à obra de arte visual, uma vez que os problemas de avaliação e valor atingem ambos os tipos de arte. Alguns exemplos serão dados, sempre que possível, para facilitar a leitura.
} 
de valor. Em segundo momento, no terceiro capítulo, o foco será dado à questão da autonomia do artista e da obra de arte. Nessa direção, esperou-se desdobrar de acordo com suporte teórico como o artista se movimenta com (ou sem) autonomia dentro de um campo de poder. No quarto capítulo, será abordada a questão do julgamento do gosto e como ele afeta diretamente leitores (sejam eles universitários ou estudantes do ensino básico). A partir daí, discutiu-se sobre como a classificação de valor (ou não) pode reverberar nos espaços de ensino.

Diante desse panorama, o objetivo central do estudo foi, portanto, desdobrar os temas aqui expostos a fim de compreender melhor o lugar da arte e seus critérios de avaliação dentro de alguns dispositivos de poder, que, por vezes, exercem uma "violência simbólica" (BOURDIEU, 1989), principalmente sobre aqueles que ocupam espaços de ensino, como estudantes universitários ou de ensino básico.

Com isso, busca-se também entender a realidade do leitor brasileiro hoje e refletir sobre como essas questões podem interferir na sua rotina e na educação seja na aula de Artes ou de Literatura - , sobretudo, no caso do estudante universitário da área de Humanidades ${ }^{2}$ ou até mesmo estudantes do Ensino Básico brasileiro. Aproveito para destacar que toda problematização que faço a partir daqui procura levar em conta, em especial, a posição e participação atual do leitor diante desse contexto que envolve "as regras da arte"3 (BOURDIEU, 2005).

\section{Sobre a queda da auréola: avaliação e valorização da arte e do texto literário}

Quais critérios definem se uma obra de arte possui valor ou não? Ao atribuir valor a uma obra, estaríamos valorizando ou avaliando esta? Diante do exposto inicialmente, vale questionarmos qual a diferença entre valor e valorização relacionados à obra de arte, uma vez que os critérios usados para essas duas ações podem ser diferentes. Certamente, no campo da arte, existe uma tensão entre valorizar e avaliar, o que produz outro campo, segundo Bourdieu (2005) que se apresenta como um jogo, cujas regras nem sempre estão bem definidas.

Como ponto de partida para esse debate, faz-se válido destacar que se existe o jogo e "as regras da arte", como sugere Bourdieu (2005), é importante dizer que este texto ocupa lugar no time daqueles que acreditam que a arte não depende de auréola para ser considerada de valor, embora se saiba que esta é uma discussão bastante longa para o campo artístico. Tão longa que Platão (1973) já discutia em sua obra A República o valor do poeta na sociedade. Para desconsolo dos inconsoláveis românticos franceses, apaixonados por Vitor Hugo, o livro X, que ficou conhecido

\footnotetext{
2 Na pesquisa de doutorado que venho desenvolvendo - com previsão de conclusão para 2020 - entrevisto estudantes do Curso de Letras de duas Universidades brasileiras e uma irlandesa, a fim de compreender e problematizar como essas estruturas do campo literário e campo de poder (BOURDIEU, 2005) estão internalizadas no discurso de leitores universitários atualmente. Neste artigo, porém, falarei de modo mais geral sobre o perfil do leitor brasileiro, mas sempre que possível trago essa reflexão para os estudantes leitores universitários e contexto do ensino de Literatura, estendendo a reflexão também aos estudantes de ensino básico e ambiente escolar.

3 Esta expressão aparecerá algumas vezes ao longo do texto e vem de uma das obras centrais de Bourdieu, que logo será citada. Em As Regras da Arte, o autor considera vários fatores determinantes envolvidos no entorno de uma obra de arte e como isso é atravessado pela luta de classes e campo de poder, já estabelecidos socialmente. Quando uso esta expressão estou me referindo, portanto, a todo esse contexto de regras que envolvem a obra de arte, seja ela do campo literário ou das artes visuais.
} 
como "A expulsão dos poetas", põe em xeque a hierarquia que confere ao poeta 4 o título de "conhecedor da realidade". Desde então esse debate continua com variações e desdobramentos diversos, bem como, ao que parece, continuam também algumas dicotomias entre arte com auréola/arte sem auréola; arte de valor/arte sem valor. Dualidade esta que podemos ler também no campo da literatura como: literatura clássica/literatura popular; cânone/best-seller; literatura de valor/literatura de massa; e por aí segue o jogo de opostos tão bem ironizado no poema de Baudelaire (1995). Nesse sentido, faz-se importante reconhecer e compreender melhor aqui a fragilidade de alguns critérios que conferem desde muito tempo valor a uma obra, enquanto renegam isso a tantas outras no momento da avaliação. Por exemplo, o que (e quem) define Dom Casmurro, de Machado de Assis, como obra literária de valor e O Alquimista, de Paulo Coelho, como obra literária de valor questionável? Ou nas artes visuais, o que define a obra O nascimento de Vênus (1483), de Sandro Botticelli como arte de valor? Enquanto ao mesmo tempo se questiona o valor, sobretudo a nudez, de obras e performances de outros artistas? Longe de negar a qualidade dessas obras citadas aqui, estou apenas apresentando exemplos para que possamos problematizar a distinção dada a algumas obras e negada a outras. Como ocorre esse processo? Qual critério concede ao artista uma auréola?

Voltando a pensar no poema epígrafe (que por sinal será retomado durante todo o texto), se visualizarmos a imagem que Baudelaire (1995) propõe em seu poema em prosa, publicado pela primeira vez em 1869, veremos um homem que perde sua auréola e parece comemorar: "há males que vêm para o bem". A auréola confere a ele dignidade, merecimento. Ora, estamos diante de um dos eleitos! Por isso, provavelmente, o espanto do interlocutor da conversa que se admira ao ver nobre poeta em lugar suspeito. "Você por aqui, meu caro?": Esse eleito responde convicto e deixa claro que prefere ser igualzinho a este que the reconhece, pois estar livre à devassidão, como os simples mortais, muito lhe agrada. Seria então, antes de perder a auréola, um deus? Claramente, Baudelaire (1995) faz uma bela analogia ao poeta sacralizado, reconhecido, digno de honra e, portanto, distante da maioria dos seres mortais. Perder a auréola para ele é prazeroso e ver alguém a recolhendo do chão e tomando para si, mais ainda. Hoje, podemos estender essa metáfora aos artistas em geral, visto que toda essa cena nos remete ao amplo debate sobre o valor da arte. Em contrapartida, a mesma cena implica também em outro movimento pertinente na pós-modernidade: o levante de grupos conservadoristas que buscam ainda o sagrado da arte e negam, com isso, sua própria história. Baudelaire (1995) debocha desse grupo ao comemorar a queda da auréola, o que representa para este trabalho um convite à problematização do tema.

De acordo com Wellek e Warren (2003), no livro Teoria da Literatura e metodologia dos estudos literários, "dar valor" e "valorizar" são coisas diferentes. Ao nos interessarmos por uma obra literária, estamos valorizando positivamente esta. Assim correu durante a história da humanidade: por motivos e interesses diversos, as pessoas

\footnotetext{
4 Pensando nos debates de hoje, por poeta estou entendendo a figura do artista e escritor literário.

$5 \quad$ Nas primeiras edições do livro de Wellek e Warren, os termos apresentados foram "valorar" e "valoração". Nessa última edição a qual faço uso, de 2003, a expressão foi traduzida como avaliar e avaliação.
} 
valorizaram livros de modo positivo. Em outra direção, quando avaliamos uma obra, estamos dando valor a ela. Assim, ao avaliar, poderemos agregar valor positivo ou negativo. Valorizar todos fazem, mas avaliar, somente os críticos literários, filósofos e artistas, segundo os autores. "De qualquer modo, passamos da experiência do interesse para o ato do julgamento" (WELLEK \& WARREN, 2003, p. 324). Ou seja, a partir da avaliação, muito diferente da valorização, nós entramos num jogo de hierarquia, em que algumas obras serão bem avaliadas e outras nem tanto (aqui, podemos usar como exemplo a distinção entre obras clássicas e best-sellers que não comumente negados em seu possível valor). O que intriga ao pensar no panorama da arte no Brasil nos anos 2010 é que alguns grupos, mesmo não sendo profissionais da área como citam os autores, passaram a não só valorizar, mas também a avaliar obras artísticas, o que gera, em muitos casos, uma distorção de critérios e polêmicas no entorno de obras de $\operatorname{arte}^{6}$ que resultam na censura artística, velha conhecida em nossa sociedade.

Pensando agora no campo literário, logo abaixo, pode-se analisar um gráfico produzido por Cortina em uma larga pesquisa apresentada no livro Perfil do leitor brasileiro contemporâneo, com levantamento geral dos autores mais vendidos no Brasil entre o período de 1966 a 2010.

Gráfico 7 - Levantamento dos autores mais vendidos (1966 a 2010)

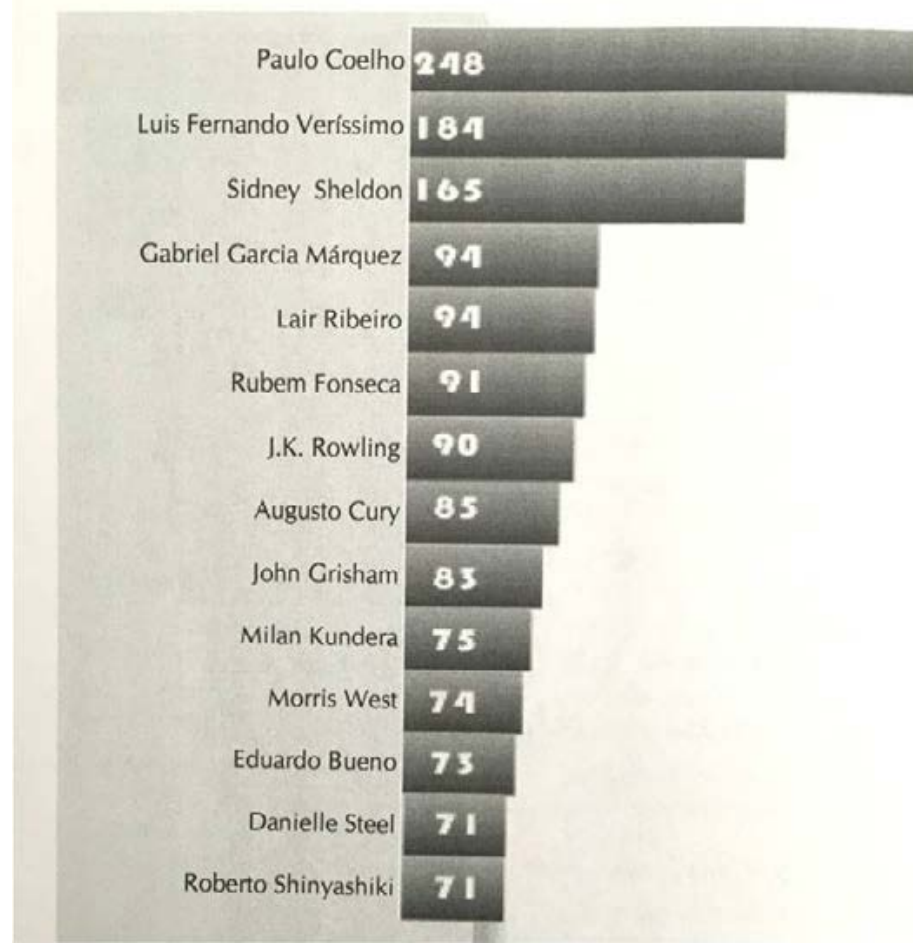

Fig. 1 - Perfil do leitor brasileiro contemporâneo (CORTINA, 2014, p.375).

Podemos notar que este gráfico está diretamente ligado à questão da valorização dos autores, independente da crítica literária, visto que Paulo Coelho, por exemplo, vem recebendo julgamento de valor negativo há algum tempo no campo 
da crítica literária, enquanto continua se destacando exponencialmente no gosto popular nacional e internacional. Sobre isso, Tzevetan Todorov (2010) em $O$ perigo da literatura diz:

De um lado, o sucesso comercial; do outro, as qualidades puramente artísticas. Tudo se passa como se a incompatibilidade entre as duas fosse evidente por si só, a ponto de a acolhida favorável reservada a um livro por um grande número de leitores tornar-se o sinal de seu fracasso no plano da arte, o que provoca o desprezo ou o silêncio da crítica (TODOROV, 2010, p.67).

A crítica do autor acima citado reivindica um equilíbrio entre os critérios avaliativos que conferem valor a uma obra, pois esse descompasso se reflete também, no ensino da Literatura e por vezes até no juízo de valor do próprio leitor. Além disso, denuncia também um paradoxo encontrado no campo da arte, quando obras que atingem sucesso comercial passam a ser, quase que na mesma proporção, ignoradas no campo "sagrado" acadêmico.

Outro problema que aqui desponta é que o desdobramento da avaliação de um objeto literário torna-se por vezes a avaliação de quem o lê. Teria o leitor também uma auréola? Poderíamos até parodiar o poema de Baudelaire (1995), imaginando outra cena bem possível em uma livraria:

- O quê? Você por aqui, meu caro? Num lugar suspeito? Você, o leitor de Machado de Assis? Na prateleira de Paulo Coelho? Você, o conhecedor de Shakespeare, prestes a comprar O diário de uma paixão, de Nicholas Sparks? Na verdade, tenho de surpreender-me!

Nesse contexto do processo de avaliação, muitas definições ficam comprometidas pelos critérios, que podem mudar conforme grupo de avaliadores, momento histórico, classe social, entre tantos outros possíveis fatores. No caso do gráfico acima, estamos nos baseando naquilo que foi vendido, o que passa pelo fator de avaliação também das editoras e livrarias. Antes de chegar à prateleira para a valorização lou não) do leitor, ocorre o processo de avaliação do mercado. No entorno de uma obra, existe também o esforço comercial em propagandeá-la e evidenciá-la mais que outras, dependendo do público alvo e meta de venda ${ }^{7}$. Num museu, por exemplo, obras de maior renome ficam destaque na exposição e direcionam o olhar de quem ali circula. Do mesmo modo, essas mesmas obras postas em evidência (como Mona Lisa ou A Gioconda, de Leonardo da Vinci (1503-1506), no Museu do Louvre em Paris, por exemplo) são comercializadas e estampadas em diferentes produtos a serem levados para casa ao final da visita (a exemplo de cartões postais, canetas, bolsas, canecas, entre outros produtos).

Relacionado a isso, em outro exemplo interessante apresentado no livro Cultura Letrada de Márcia Abreu (2006), a autora conta que um livro de Machado de Assis foi enviado em 1999 sem identificação de sua autoria a algumas editoras brasileiras com o pedido de ser publicado. Todas elas negaram a obra. Ou seja, naquele contexto

7 Há uma simplificação da questão aqui, mas todos os autores citados em referencial se aprofundam na questão da influência do mercado nesse processo. 
e momento, a obra de Machado de Assis, considerado maior escritor da Literatura Brasileira, não foi considerada de valor. Na ocasião, a maioria das editoras que chegou a responder não deixou claro quais eram os motivos da negativa, mesmo garantindo que o livro foi lido por especialistas da literatura (ABREU, 2006). Em sua escrita, muito didática, Márcia Abreu vai direto ao ponto:

[...] O que se considera uma história bem narrada em uma tribo africana não é o que se considera bem narrada em Paris; o enredo que emociona uma jovem de 15 anos não é o que traz lágrimas aos olhos de um professor de 60 anos; o que um crítico literário carioca identifica como um uso sofisticado de linguagem não é compreendido por um nordestino analfabeto. $O$ problema é que o parisiense, o professor, o crítico literário, o homem maduro têm mais prestígio social que o africano iletrado, a jovem, o lavrador. Por isso conseguiram que seu modo de ler, sua apreciação estética, sua forma de se emocionar, seus textos preferidos fossem vistos como o único (ou o correto) modelo de ler e de sentir (ABREU, 2006, p.58).

Logo, parece que a concessão da auréola parte de um grupo seleto de pessoas que gozam de prestígio e distinção e se sentem neste espaço de poder aptos a operar o julgamento do gosto. Para os autores Wellek \& Warren (2003), também teóricos literários, é muito difícil estabelecer critérios que sejam totalmente coerentes ao avaliar uma obra literária, pois se tomamos como base apenas a estética do texto, por exemplo, estamos ignorando o conteúdo e elevando apenas a forma. Por outro lado, se ignorarmos a estética, podemos correr o risco de perder o senso da qualidade literária, devendo dar valor a qualquer que seja a obra, independente da forma apresentada. Assim, embora a discussão represente um nevoeiro de incertezas, podemos afirmar que a avaliação sempre apresenta um motivo de ressalva, questionamento e suspeita. Ao pensar na avaliação de uma obra de arte (seja o livro, quadro, música, entre outras manifestações artísticas), vale problematizar quem está avaliando e qual engrenagem social está por trás deste avaliador, uma vez que, segundo Giorgio Agamben (2009), existe um "dispositivo de poder" em alguns campos que podem operar aquilo que Bourdieu (1989) chama de "violência simbólica".

Os autores Wellek \& Warren (2003) fazem uma analogia entre a hierarquia do valor na Literatura e a hierarquia das classes sociais: "A hierarquia dentro de uma classe é sempre, por assim dizer, competitiva e relativa" (WELLEK \& WARREN, 2003, p. 337). Esta mesma relação também é denunciada por Bourdieu em toda sua obra. Para ele, a hierarquia apresentada a partir da avaliação que se faz da arte, bem como da literatura e seus leitores também pode reforçar um movimento de privilégio (concedido a poucos), o que para Bourdieu (1989) seria um "poder simbólico".

Portanto, para pensarmos nessa dicotomia "valorizar" e "avaliar", Wellek \& Warren (2003) ajudam a refletir dizendo que, embora assumir o relativismo seja ruim, ao analisarmos a história das avaliações, precisamos admitir uma inconstância ${ }^{8}$ dos critérios de avaliação que precisa ser questionada frequentemente. Os autores sugerem, nesse caso, a aceitação da existência de uma complementariedade entre esses dois polos:

8 Essa mesma inconstância pode ser observada na história da arte, que registra o julgamento e censura de muitas obras que foram do profano ao sagrado através dos tempos e hoje são consideradas patrimônios artísticos para a humanidade. 


\begin{abstract}
A distinção que precisamos fazer, parece, é entre o julgamento aberto e o julgamento implícito - que não deve ser igualada à distinção entre julgamentos conscientes e inconscientes. Há um julgamento de sensibilidade e há um julgamento arrazoado, de raciocínio. Não existe uma contradição necessária entre eles: uma sensibilidade não pode alcançar muita força crítica sem ser suscetível de considerável formulação teórica generalizada, e um julgamento arrazoado, em questões de literatura, só pode ser formulado com base em alguma sensibilidade, imediata ou derivada (WELLEK \& WARREN, 2003, p. 343).
\end{abstract}

Diante disso, se lembrarmos o romance $A$ insustentável leveza do ser, de Milan Kundera ${ }^{9}$ (2008), quando, citando Parmênides, o autor reflete sobre o mundo dividido em pares de contrários e os mistérios trazidos por esses pares, poderemos compreender melhor essa proposta de complementaridade. Nesse caso, assim como peso e leveza andam juntos, embora pareçam opostos, podemos pensar que valorização e a avaliação se correlacionam e podem inclusive estabelecer um par de complementares. Ou seja, tanto a sensibilidade do gosto quanto critérios técnicos devem ser levados em conta quando se trata de avaliar e valorizar a arte. O que não deve passar despercebido é de onde vem o julgamento e qual dispositivo de poder pode estar por trás dele.

Nesse panorama, o que não podemos perder de vista - enquanto preocupados com as lentes da teoria, crítica literária e ensino de Literatura e Artes - é que a avaliação deve ser problematizada em seus critérios, para que o julgamento não se torne mais uma das tantas ferramentas de violência simbólica já citada (BOURDIEU, 1989) contra os "reles mortais" que não possuem e nem fazem questão de possuir a auréola, deixada na lama por Baudelaire (1995), que ironiza e renega a avaliação a ele feita. A sacralização da arte nesse contexto privilegia a avaliação e julgamento de gosto por parte de uns, desqualificando outros grupos sociais (e aqui podemos incluir tanto o público quanto o próprio artista).

Dessa forma, se, por um lado, precisamos assumir o quanto a avaliação de uma obra pode ser importante e complementar no sentido da razão e sensibilidade, por outro, todavia, precisamos também associar qualquer avaliação ao contexto social e campo de poder em que os avaliadores e a obra artística estão inseridos, respeitando diversidades e culturas outras. Tudo isso, principalmente no caso da pesquisa da qual este trabalho faz parte, sem ignorar o modo como isso atinge a vida do leitor e o ensino da Literatura e das Artes. A tarefa é árdua, mas necessária, ainda mais em tempos de crise sobre o lugar da Arte na vida das pessoas e em sala de aula.

\title{
3 Sobre leitura literária e "as regras da arte": o campo de poder e a autonomia da obra de arte
}

No que tange ao conceito de violência simbólica, vale aqui dar destaque ao livro de Pierre Bourdieu (1996), As Regras da Arte, que fala sobre o campo da arte dentro do campo do poder:

Muitas das práticas e das representações dos artistas e dos escritores (por exemplo, sua ambivalência tanto em relação ao 'povo' quanto em relação aos

9 KUNDERA, Milan. A insustentável leveza do ser. São Paulo: Companhia da Letras, 2008. 
'burgueses') não deixam explicar senão por referência ao campo do poder, no interior do qual o próprio campo literário (etc.) ocupa uma posição dominada. O campo do poder é o espaço das relações de força entre agentes ou instituições que têm em comum possuir o capital necessário para ocupar posições dominantes nos diferentes campos (econômico ou cultural, especialmente) (BOURDIEU, 1996, p.244).

Nessa direção, é viável pensar que o processo de avaliação apresentado anteriormente não se trata de um recurso ingênuo, mas sim de uma ferramenta para que, possivelmente, este capital mencionado por Bourdieu (1996) continue ocupando seu lugar de domínio. Por isso, obras artísticas que tocam o gosto do "povo", independente dos critérios estéticos serem bem atendidos, por exemplo, podem nem sempre coincidir com as obras do topo no ranking da avaliação e julgamento de valor pela crítica literária (instituição de poder). No Brasil, poderíamos citar a literatura popular representada pela poesia de cordel. Esse é, inclusive, outro exemplo apresentado na obra de Márcia Abreu (2003). Analisando vários cordéis, a autora comprova o valor estético na produção literária, analisando sua forma, porém questiona a avaliação feita dessas obras, visto que, por serem consideradas "literatura popular", são estigmatizadas como de baixa qualidade, por virem de "um lugar suspeito", nos termos de Baudelaire (1995). Isso! Aquele mesmo lugar onde encontramos o poeta sem auréola mencionado no poema de epígrafe.

E como fica aquele leitor que gosta da poesia de cordel diante desse processo? Estamos claramente diante de um campo de sacralização da arte em prol de um grupo que exerce um poder simbólico na sociedade. Para além dessa imagem do poeta em lugar suspeito, se pensarmos na figura desse leitor, essa distinção também se estende a ele, pois aquele que "consome" este tipo de leitura (nesse caso, o cordel, mas poderíamos pensar também na literatura de massa, best-sellers, entre outros) também será taxado como leitor pouco distinto, sem auréola, sem prestígio. Esse movimento reforça ainda no século XXI a ideia de arte sagrada de séculos passados, o que afasta a obra de arte do lugar de uso comum e a coloca em local inatingível.

Se a avaliação agora se volta à figura do leitor, analisar a competência deste exige compreender também sua cultura e contexto social, respeitando, desse modo, sua construção histórica ${ }^{10}$. Algumas tribos indígenas e comunidades pelo mundo ainda vivem sem a necessidade da escrita e leitura em sua cultura, por exemplo. Seria essa uma comunidade sem prestígio? De acordo com essa avaliação, provavelmente. No caso do leitor, o problema está não só na desqualificação dele consequente dessa avaliação, mas também no fato de que muitos outros leitores podem, com isso, sentirem-se motivados a alcançar essa tal "dignidade". Serão os leitores ávidos por encontrarem também uma auréola de leitor, assim como o $\mathrm{X}$ e $\mathrm{Z}$ citados por Baudelaire (1995).

Embora as perguntas aqui lançadas sempre se voltem para esse frágil leitor, é preciso entender o processo pelo ponto de vista da obra de arte para compreender melhor, a partir disso, seu desdobramento. Cabe aqui pensar, portanto, na autonomia da obra de arte, já que nem toda ela se subordina às regras impostas pelo campo. 
Muitas obras transcendem esse jogo de avaliação e ainda assim atingem certo prestígio ou se deslocam com o tempo no quadro classificatório que distingue arte e não arte. O que ocorre? Elas conseguem criar suas próprias regras e códigos, não dependendo apenas de uma exigência de mercado. Como exemplo, podemos pensar em Marcel Duchamp ${ }^{11}$ que, representando as vanguardas, implodiu as regras no meio da arte e ainda assim ganhou um espaço memorável na história da arte.

Outros artistas, como ele, também atingem autonomia quando rompem regras dentro de um campo social e ainda assim conseguem se reestruturar com novas regras para sua própria arte. Um exemplo visual citado por Bourdieu (2005) seria Gustave Coubert, com a obra "O ateliê do artista"12 de 1855, que rompe totalmente com a lógica da obra de arte na época ao inserir o próprio artista como peça-chave da tela. A princípio, essa inovação gera o estranhamento negativo, porém, de outro lado, consegue por meio de novas técnicas se manterem no campo artístico.

Para pensar no campo literário, vejamos outro gráfico, agora com os títulos mais vendidos no Brasil entre anos 2000 e 2010.

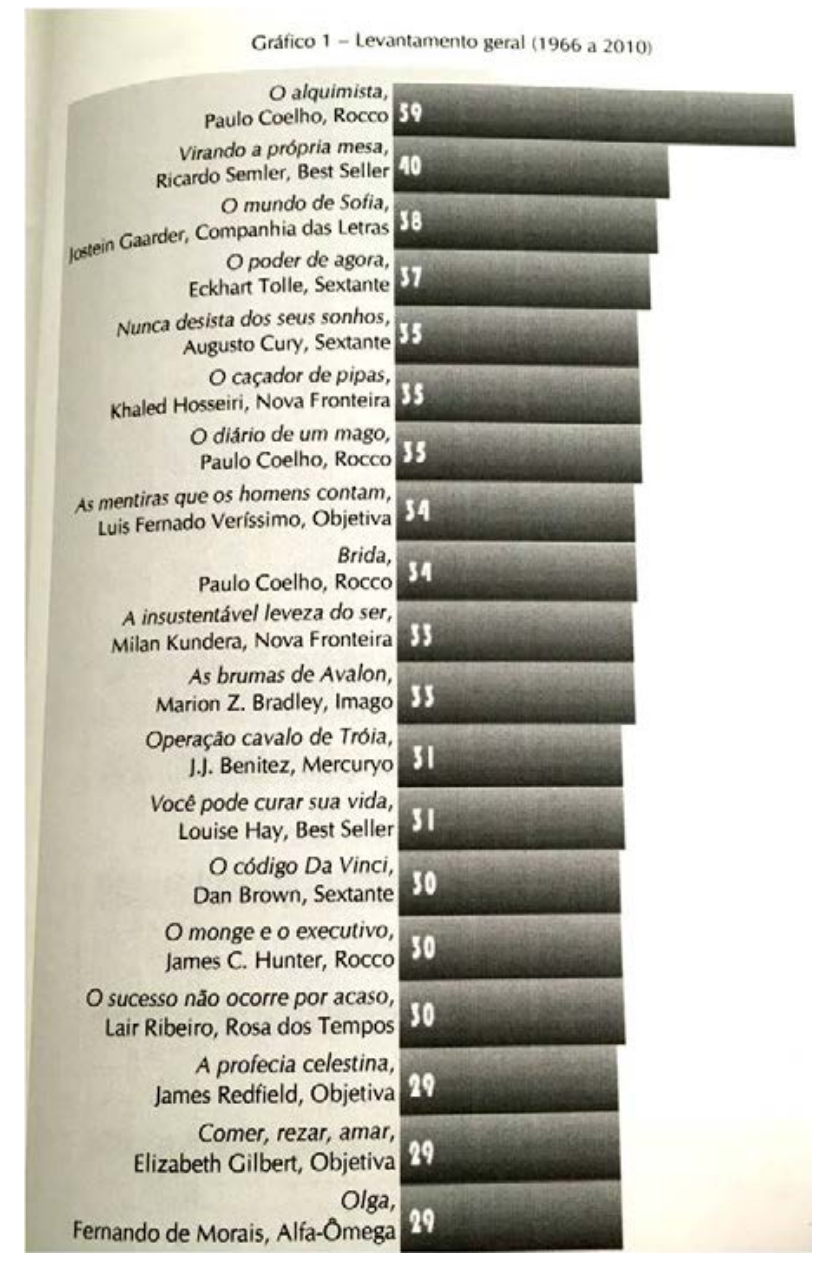

Fig. 2 - Perfil do leitor brasileiro contemporâneo (CORTINA, 2014, p.376).

\footnotetext{
11 Duas obras de Marcel Duchamp que marcaram esse momento de desconstrução nas artes (conhecido como Dadaísmo) podem servir aqui como exemplo, são elas: Mictório (1917) e Roda de Bicicleta (1913). Ambas tratam objetos aleatórios como arte.

12 Nessa obra, a quebra com os paradigmas até então em voga na arte das telas a óleo se dá pela representação do próprio artista em seu ateliê produzindo uma obra. A metalinguagem (o pintor apresentado dentro da sua pintura) causa estranhamento e rompe com a lógica daquele momento.
} 
Analisando esta lista, poderíamos dizer que algumas obras rompem com "as regras da arte" e atingem certa autonomia? Ainda não se pode ter certeza dado o período tão atual, mas é possível arriscar a dizer que Milan Kundera, que ocupa o 10은 lugar da lista, rompeu com "as regras da arte" e atingiu certa autonomia, quando, além de ser avaliado positivamente pela crítica literária, alcança também popularidade entre os leitores. Ou seja, vemos um autor que, a exemplo de Baudelaire (1995), recebe a auréola da dignidade em sua avaliação, mas ao mesmo tempo anda por lugar "suspeito", como a lista dos mais vendidos.

No Brasil, podemos lembrar a má avaliação que Machado de Assis teve inicialmente por parte da crítica em suas primeiras produções, quando julgavam que ele tinha vocabulário europeu e pouco retratava o Brasil ${ }^{13}$. Mais tarde o mesmo autor rompe com essa avaliação e torna-se principal referência da Literatura no Brasil, sendo logo reconhecido também pela própria crítica. Temos aí um exemplo de arte literária que ganha autonomia e rompe com a lógica da avaliação, mantendo se numa posição de privilégio dentro do campo da arte. No caso de Machado de Assis, ao mesmo tempo em que era recebido pela crítica de maneira positiva (nessa segunda fase), continuava na época sendo lido e reconhecido popularmente.

Nesses casos, a popularidade de uma obra ajuda a romper a ideia de sacralização da arte e demonstra a capacidade de uma obra em criar suas próprias regras, ganhando autonomia e indo além dos muros impostos pelas regras que dividem a literatura-sim e literatura-não, arte-sim e arte-não. Machado de Assis, como alguns outros artistas, conseguem, quando atingem essa autonomia, alcançar uma boa avaliação e boa valorização. Além de Kundera, poderíamos averiguar mais a fundo também a presença de Luis Fernando Veríssimo nesta lista, visto que o autor contemporâneo brasileiro, além de ocupar o 8 lugar, já tem sido bastante estudado no campo acadêmico $^{14}$. Ademais, na lista de leituras para exames de vestibulares no Brasil (outro espaço onde se opera o poder simbólico da avaliação), Luis Fernando Veríssimo tem aparecido frequentemente como indicação de leitura.

Mas voltando a Duchamp, tanto Antoine Compagnon (2010) no livro Os cinco paradoxos da modernidade quanto Beatriz Sarlo em Cenas da vida pós-moderna, entre outros autores, citam seu exemplo como grande problematizador do valor (no sentido da avaliação) da arte: "Mais que nenhum outro, Duchamp contribuiu para esvaziar a criação de seu mistério e retirar, do artista, a aura do gênio, herdada do romantismo e da qual continuava tributária a maioria dos surrealistas." (COMPAGNON, 2010, p.95) Foi por meio de um mictório pendurado na parede - entre outras provocações - que o artista chamou atenção para uma estrutura que carecia (e ainda carece) de problematização: "O artista decide, pois, o que produz, mas o mercado decide se se trata de arte. Testemunhando o papel preeminente do mercado da arte, Duchamp, que se autointitulava 'antiartista', destruiu a oposição entre a arte e a não arte." (COMPAGNON, 2010, p.95) Se compararmos esse movimento de Duchamp com o debate atual sobre a arte no Brasil, vamos nos deparar com questões similares que ainda giram em torno desse paradoxo arte e não arte.

\footnotetext{
13 Essa história é comentada por Roberto Schwarz numa entrevista para o Programa obra aberta (TV Cultura) Disponível em < https://www.youtube. com/watch?v=m5y1Tc5sKN8> último acesso em maio de 2015.

14 A fim de averiguar superficialmente se estes autores (Kundera e Veríssimo) são tão populares quanto discutidos no âmbito acadêmico, podemos encontrar na rede várias teses e dissertações publicadas cujo tema central circula em torno de obras dos referidos autores.
} 
No entanto, para complementar o debate, quando se trata dessa arte autônoma e provocativa de Duchamp, Tzevetan Todorov em $O$ perigo da literatura faz uma ressalva bem interessante, visto que preza pela relação da obra com a realidade. Para ele, a arte não deveria ser apenas a pura manifestação de um indivíduo, pois isso, segundo ele, "torna vã toda procura por sentido e verdade" (TODOROV, 2010, p. 69). O autor não nega a importância do processo de autonomia da obra de arte, mas questiona os caminhos da arte pós-moderna que, muitas vezes, para atingir sua autonomia e romper com a lógica da estética, acaba por esvaziar-se de sentido, o que não nos ajuda do ponto de vista de valorizar aquilo que a literatura tem de mais interessante: o poder de representação e comunicação inesgotável com a realidade. Para Todorov (2010), portanto, ainda que a obra de arte se movimente de modo autônomo, é importante que ela tenha algo a dizer e se relacione de algum modo com a realidade.

O que vale destacar aqui neste tópico é que, independente da autonomia que a obra de arte atinja, ela ainda estará a serviço de um sistema simbólico.

\begin{abstract}
É enquanto instrumentos estruturados e estruturantes de comunicação e de conhecimento que os sistemas simbólicos cumprem a sua função política de instrumentos de imposição ou de legitimação da dominação, que contribuem para assegurar a dominação de uma classe sobre outra (violência simbólica) dando o reforço da sua própria força às relações de força que as fundamentam e contribuindo assim, segundo a expressão de Weber, para a 'domesticação dos dominados' (BOURDIEU, 1989, p.11).
\end{abstract}

Diante disso, não se pode perder de vista, neste contexto, que o campo da arte, independente do movimento autônomo ou não do artista, está inserido num sistema simbólico que implica numa luta de classes e ideologias que, por vezes, se esconde por detrás da avaliação que confere a uma obra o "extrato" de arte ou não arte.

\title{
4 Sobre o leitor e a auréola: o princípio da boa vontade cultural
}

Seguindo a linha de raciocínio de Bourdieu, chegamos a outro ponto: a domesticação dos dominados. Todorov (2010) também questiona como tem se dado essa avaliação de que falamos até aqui da literatura. Para ele, a literatura foi reduzida ao absurdo a partir do momento em que se deixou de lado a mensagem e o conteúdo para se pensar na forma, de modo a colocar a literatura, de fato, em posição secundária à própria teoria. O autor, assim como Bourdieu, Baudelaire (1995) e outros problematiza o lugar sagrado da arte e recobra a importância de torná-la mais próxima das pessoas, principalmente em sala de aula ${ }^{15}$, quando se trata de educação escolar e universitária.

Neste ponto, Todorov (2010) chega muito perto da pesquisa maior da qual este artigo faz parte. O que gera preocupação diante de todo esse panorama aqui apresentado é pensar, com base na experiência com ensino de Literatura, que muitos estudantes (sobretudo universitários) ainda sentem necessidade de estabelecer essa

\footnotetext{
15 Embora minha pesquisa de doutorado cubra mais especificamente o ambiente universitário, entrevistando estudantes de graduação de curso da área das ciências humanas, também abordo aqui questões pertinentes ao ambiente escolar quando se trata do ensino de Literatura nas escolas, por acreditar que tais realidades estão relacionadas entre si. Desse modo, o comportamento incentivado na escola durante aulas de Literatura e Língua Portuguesa pode afetar diretamente os objetivos dos estudantes universitários recém chegados ao ambiente acadêmico em busca dessa cultura dominante.
} 
classificação arte e não arte, como forma de se reafirmar como conhecedor daquilo que "é arte". Muitos deles - aqueles que estão interessados em conhecer o campo da arte - renegam, por exemplo, best-sellers, criticam Paulo Coelho, sem antes fazer sequer uma leitura ou problematização maior sobre o assunto e critérios que avaliam essas obras como negativas. Ao que parece, esse campo de poder ainda exerce força no julgamento de valor da arte e isso não atinge apenas os "eleitos", mas também aqueles que - talvez ingenuamente - querem em algum momento fazer parte deste grupo de seletos leitores que conhecem a "arte sagrada". Tal comportamento pode estar presente tanto no ambiente acadêmico das Universidades quanto nas escolas, fomentado muitas vezes pelos professores. No entanto, está implícita nesse movimento, segundo Bourdieu, uma luta de classes que ocorre por meio de conflitos simbólicos. Nesse caso, ser um leitor distinto ou não é um conflito simbólico que, indiretamente, define a classe social do sujeito, uma vez que a educação é, indiscutivelmente, para o autor, uma questão definitiva de classe.

Paralelo a isso, mesmo havendo resistência de alguns grupos, existe um esforço simbólico por parte de integrantes desse sistema (especialistas e artistas) que busca legitimar uma classe dominante dentro do campo da arte. Desse modo, engrenagens que se movimentam dentro desse campo também trabalham para a produção ideológica em favor de uma cultura dominante. Esse poder simbólico opera diretamente nas visões de mundo que circulam pela sociedade. Assim, quando um estudante do curso de Letras, por exemplo, se diz um leitor distinto e sonha em ter uma biblioteca com todos os "clássicos", vale estarmos atentos à origem desse desejo, pois, possivelmente, ele seja fruto desse movimento da distinção cultural que dá prestígio aos que lêem os "clássicos" e desprestígio aos que lêem o que é de gosto popular. Nessa direção é que Paulo Coelho tem sido ignorado no Brasil por muitos estudantes da área de Letras e até mesmo pelo campo acadêmico. Comportamento este que pode advir do ambiente escolar também. Temos aí um possível exemplo que resulta de uma dominação cultural, em outras palavras, a domesticação do dominado. Seja na Educação Básica ou Ensino Superior, em que medida o ensino de Artes e Literatura têm contribuído para essa sacralização do que é arte?

O esforço do estudante (seja no ambiente escolar ou universitário) que quer ser visto como leitor distinto, que sonha com a biblioteca ou o constrangimento do estudante que diz "não nasci para essa coisa de leitura" é chamado por Bourdieu (2013) de "princípio da boa vontade cultural", o que evidencia o quanto esse campo de poder ainda exerce uma violência simbólica não somente excluindo artistas e obras a partir de critérios discutíveis, mas também alimentando certa "promessa" a leitores que buscam ainda por uma auréola. Nesse caso, não seria de admirar que o X e o Z que Baudelaire (1995) pede para que imaginemos seja também um estudante que busca com todas as forças entrar para o grupo dos leitores eleitos. Do mesmo modo, por outro lado, poderia haver ainda o personagem $Y$, que é aquele que só sabe respeitar a auréola, mas que nunca nem a tocaria, por não se achar digno dela. Quantos estudantes da área de Letras e Artes visuais ainda acreditam no poder das auréolas? particularmente freqüente dos testemunhos mais incondicionais de docili- 
dade cultural - escolha de amigos 'instruídos', gosto por espetáculos 'educativos' ou 'instrutivos' - muitas vezes, acompanhados por um sentimento de indignidade ('a pintura é boa, mas é difícil, etc.), proporcional ao respeito concedido (BOURDIEU, 2013, p.300).

É certo que a lista dos livros mais vendidos, apresentada anteriormente, não nos diz nada a respeito dessa boa vontade cultural, mas é a partir dessa discussão entre o interesse popular na compra de determinados livros e o processo de avaliação de uma obra que podemos pensar sobre como os leitores lidam com essas regras da arte que são também jogos de poder simbólico. Pensando no contexto de sala de aula, muito leitores universitários apreciam alguns títulos que compõem a lista apresentada ( $O$ caçador de pipas, Harry Potter e a pedra filosofal, O alquimista, entre outros), mas se esforçavam por justificar rapidamente numa conversa "gosto, mas sei que isto não é literatura". Ou seja, a discussão que assombra muitos teóricos acerca da avaliação também está presente na vida de estudantes da área e isso pode vir inclusive como origem de um comportamento já reforçado na escola. Alguns desses estudantes universitários recém-chegados ao ambiente acadêmico se esforçam para entender o livro clássico/canônico e reconhecem logo seu "valor", mas são vários os casos em que isso ocorre sem sequer haver questionamento sobre os critérios usados nessa avaliação. Há um respeito por Machado de Assis tão inquestionável que ler Machado de Assis para respeitá-lo passou a ser dispensável. Nesse caso, vemos mais obediência ao cânone que valorização a ele. Pelo que parece, há uma confiança cega nos eleitos, àqueles que sabem o que é arte e que escolhem por nós, muitas vezes, as obras que devemos "gostar" ou não. Em que medida o gosto de estudantes universitários inseridos no campo das artes está sendo domesticado? Em que medida esse gosto já está sendo domesticado desde a escola?

Poderia arriscar a dizer que dentro do ambiente acadêmico de um Curso de Letras há ainda a ditadura do gosto, visto que "Quem gosta de Paulo Coelho, bom sujeito não é", agora parodiando Dorival Caymmi. Bourdieu discute isso na obra $A$ Distinção: crítica social e julgamento (2013). Nesta, o autor entrevista e analisa o campo literário da França e como as classes sociais lidam com esse jogo da distinção e julgamento do gosto. Para ele a questão de gosto é discutível, uma vez que quanto mais alta a classe social, mais o gosto cultural desse sujeito está associado ao poder dominante da arte canônica. Enquanto, por outro lado, quanto mais baixo o acesso aos estudos, mais o gosto está associado a um repertório cultural popular. Diante de todas essas reflexões, é notável que a boa vontade cultural ainda permeie a realidade de estudantes e leitores brasileiros ${ }^{16}$ desde a escola e, no caso de estudantes do curso de Letras principalmente, parece se potencializar quando no ambiente universitário.

\section{Considerações finais: caminhos entre o empírico e científico}

Como já apontado no início, foi possível compreender e olhar mais de perto para alguns pontos que demonstram a fragilidade da avaliação de uma obra, diante

16 Estas suspeitas por enquanto ainda se tratam de confirmações empíricas, mas serão evidenciadas por meio de entrevistas ao longo da produção de minha tese para entender melhor, a partir dos discursos de leitores estudantes da área da Literatura, como a regra da arte opera no cotidiano acadêmico de hoje. 
do mercado, do crítico literário, autor/artista e, sobretudo, leitor, estudante. O que fica marcado para esta etapa do estudo é a necessidade de problematização das avaliações feitas sobre determinadas obras, bem como a importância de não perder de vista a diferença clara entre valorizar e avaliar uma obra artística. No mais, também ficou clara a importância da complementaridade da noção de valor no sentido de avaliar e valorizar.

Além disso, outra reflexão pertinente é a de que a avaliação que se dá no campo da arte não está descolada de uma luta simbólica que envolve domínio de classe e domesticação dos dominados. O julgamento do gosto cultural continua operando num sistema simbólico e reforça a sacralização da arte, o que pode resultar, entre muitos danos sociais, na censura e demérito de artistas e leitores que não possuem a tal auréola, símbolo do sagrado.

Quanto ao panorama dos estudantes e leitores no Brasil, há ainda muito que se pensar, analisar, investigar, mas ficaram aqui registradas também as principais preocupações envoltas na figura do leitor e suas escolhas. Os gráficos indicam que os leitores valorizam tanto obras desvalorizadas quanto valorizadas pela crítica literária. Nesse ponto, cabe a reflexão sobre a autonomia da obra de arte que influencia diretamente nas rupturas das regras desse jogo. Isso talvez explique o motivo pelo qual algumas obras conseguem ter apreciação do público e também da crítica, ou ao menos chamar atenção desta última, como foi o caso de Duchamp. Tal movimento só comprova a contrariedade e complexidade que envolve a avaliação de uma obra de arte.

Por fim, fica o questionamento que impulsiona este estudo para a continuidade da pesquisa: como isso tudo interfere diretamente na vida de leitores estudantes? Com certeza, alguns deles são exemplos da boa vontade cultural e domesticação de que fala Bourdieu. Cabe agora sistematizar dados, ouvir estes leitores, saber o que pensam sobre isso a fim de compreendê-los e elaborar melhor, com isso, essas discussões teóricas a partir da realidade cultural observada. São as cenas para os próximos capítulos.

\section{Referências}

ABREU, Márcia. Cultura Letrada: literatura e leitura. São Paulo: Editora Unesp, 2006.

AGAMBEM, Giorgio. O que é um dispositivo? In: O que é o contemporâneo? e outros ensaios. Chapecó, SC: Argos, 2009.

BAUDELAIRE, Charles. O Spleen de Paris. Pequenos poemas em prosa. Rio de Janeiro: Imago, 1995.

BOURDIEU, Pierre. A distinção: crítica social do julgamento. 2.ed. Porto Alegre, RS: Zouk, 2013.

BOURDIEU, Pierre. O poder simbólico. Portugal; Difel, 1989. 
BOURDIEU, Pierre. As Regras da Arte: gênese e estrutura do campo literário. São Paulo: Companhia das Letras, 1996.

COMPAGNON, Antoine. Os cinco paradoxos da modernidade. Belo Horizonte: Editora UFMG, 2010.

CORTINA, Arnaldo. Perfil do leitor brasileiro contemporâneo: os livros mais vendidos no Brasil de 1966 a 2010. Campinas, SP: Mercado das Letras, 2014.

KUNDERA, Milan. A insustentável leveza do ser. São Paulo: Companhia da Letras, 2008.

PLATÃO. A república. 2 ed. São Paulo: Difel Ed., 1973.

PROGRAMA obra aberta. TV Cultura. Entrevista com Roberto Schwarz. Disponível em: <https://www.youtube.com/watch?v=m5y1Tc5sKN8>. Acesso em maio de 2015.

TODOROV, Tzvetan. A literatura em perigo. Trad. Caio Meira. 3a. Ed. Rio de Janeiro: DIFEL, 2010.

WELLEK, René; WARREN, Austin. Teoria da literatura e metodologia dos estudos literários. São Paulo: Martins Fontes, 2003. 